\title{
Essential of Cultural (literature, Art, Music, customs ...) Negotiation as a Resources of Smart and soft Power in Age of Globalization
}

\author{
Mohammad Khosravishakib \\ Department of Persian Language and Literature, Human Science Faculty, Lorestan University, I. R. Iran \\ E-mail: M.khosravishakib@gmail.com
}

Received: 09-04-2017

Accepted: 05-06-2017

doi:10.7575/aiac.ijalel.v.6n.6p.101

Published: 01-11-2017
Advance Access Published: September 2017

URL: http://dx.doi.org/10.7575/aiac.ijalel.v.6n.6p.101

\begin{abstract}
One imperative form of public negotiation and soft authority is cultural negotiation so that contains of concepts, facts, art and additional facets of culture between people in way to shared understanding. The determination of cultural negotiation is for external country to cultivate a considerate of the population's principles and organizations in determination to shape expansive maintenance for financial and administrative aims. Cultural negotiation could reveal the depth of a public; with the intention of in other opportunity generates encouragement and effects. It can suppose that cultural negotiation flask and does a significant character in accomplishing general security purposes. This cultural diplomacy conventionally has helped to accomplish affairs between positions and other gatherings by instructing and modeling external strategy, so as to eventually organizes and acquires detailed condition and benefits in the global ground. This paper will study the process of cultural cooperation witch has been developed to increase lenient control and take how cultural negotiation has improved to the contemporary world and also encourage greater association within the peoples of other countries.
\end{abstract}

Key words: Culture, Literature, Negotiation, Soft power

\section{Introduction}

Nye (2004) believed that "Cultural assistance just now has predictable as reformed contemplation around the world on or after governments, cultural overall specialist, and investigators as proceeds to understand, inform, take in, and incentive nationwide and common addressees". Cultural negotiation is observed by way of creating universal connections and communications, recognizing systems and authority purviews in beliefs and surpassing general and national restrictions. Based on Cummings (2003) research, smart and soft power mixes general art, music, and literature plus knowledge, conviction, ethics and several other competences and customs shaped by a civilization from side to side of existence technologies. Baudrillard declared that standing of community negotiation has been developing meanwhile smart and soft power has budding out of art, music, and literature, out of national standards and strategies, and out of external procedure. (Baudrillard; 1988, 52) It appeals the important character of national negotiation as prerequisite of public negotiation. Richard (2003) in the book The First Resort of Kings perceived that cultural negotiation is a total operative training in view of its products and impressions on global connections among nation state. (Richard; 2005. 34) The analysis demonstrates that cultural negotiation assistances generate an underpinning of conviction with additional publics, which strategy creators can shape on to extent administrative, financial, and struggling arrangements. Havanjung supposed (2011) cultural negotiation cheers new populate to provide the population the advantage of the hesitation on detailed strategy subjects or requirements for association, meanwhile there is a supposition of common attention. Cultural negotiation furthermore proves nationwide standards and generates connection through publics, so that tolerate alterations in administration. Additionally, cultural negotiation can spread effective associates of external civilizations who cannot be touched over old delegation purposes. Belanger (1999) supposed that it could make available a helpful program for assistance regardless of strategy transformations, generates an unbiased policy for nation to nation connection, and helps such as a bendable, generally putative means of transportation for method with nations where political relationships have been stressed or are preoccupied. (Belanger; 1999, 3) By way of contemporary time, a novel approach of announcement in an Internet has been shaped and industrialized together with quickly developing facts machineries. This novel method of connection affords original prospects for cultural strategy creators to widen their goal audience and to endorse culture level further generally with its fresh mass media podiums. Equally, "cultural negotiation by means of facts technologies will expansion and reinforce smart and soft control if national strategy creators make practice of original announcement skills successfully and deliberately". (Beardworth; 2010. 51). To completely comprehend the importance of cultural negotiation, it is valuable to principal describe the vital concepts; Art, music, and literature as culture, Culture in Political affairs and Culture in Community Peacekeeping. Culture could be defying as multifaceted entire containing awareness, acceptance, 
art, standards, commandments, customs and conventions and every other competences and traditions shaped by people who is a associate of the world anywhere a crowd of persons is connected to every other over tenacious associations, or a enormous communal alliance distribution the infrequent ecological or practical region, issue to the identical administrative power and prevailing cultural opportunities; (Joseph; 2004, 59)Culture in Legislation is to locate culture in national external strategy such as the manifestation of a general concern, so that donates to the reification of the domestic personality, conviction organizations, planned philosophies and national character. It causes encouraging and previously prevailing philosophy in a foreign country also contains a further vigorous role in defensive and mounting general culture; (Fotopoulos; 2001. 21) Culture in Community Negotiation is a universal performer's effort to endorse the nationwide culture, to stretch influences on communal thoughts of equivalents and to shape honesty and reliability over cultural interactions. Brown (2006) says, several methods accessible for working public negotiation for instance media negotiation, computer-generated negotiation, assistance negotiation, cultural negotiation, sport negotiation and so on. Therefore, culture in general negotiation suggests that national Negotiation can be accomplished as funds of public negotiation over the multinational happenings, the art showing, and done by numerous global carnivals.

\subsection{Smart \& Soft Power}

There is a tight connection between culture and public negotiation with the intention that it start in the insight of ability. Affording to Joseph Nye, who introduced the perception of smart authority, describes authority and power as "the capability to attain one's determinations or aims" and "the capability to acquire others to do what they else would not fix. He (2001) differentiates amid lenient power and tough power grounded on the natural surroundings of performance and palpability of possessions. Permitting to this theory, authority reposes beside the variety includes; Knowledge, Pressure, Encouragement, Program Background, Magnetism, Supportive Ability. Facility Authority, the aptitude to alteration what others do, can respite on pressure of incentive. Joseph Nye's (2001) term -soft power- label the capability to form what others need, can repose on the charm of one's culture and thought or the skill to operate the program of governmental adoptions in a method that creates performers nosedive to direct particular inclinations since they appear to be also impractical. Mcguigan announces (1996) places compacted power funds on the understanding power; although soft power possessions repose on the cooperative power. (Mcguigan; 1996. 12) Hard power is a nation's financial and armed capability to acquisition and pressure, and soft power is the facility to fascinate over and done with national and philosophical petition. He (1996) also highlights the connotation of community negotiation meanwhile lenient power creates out of nation, out of national standards and strategies, and out of external process. Supplementary he (1996) instructions that superior function for data and official power is like a conversion to a different period and also he put emphasis on undersized period reactions can be perfected over and done with expending transmission competences and slender molding on the Internet, therefore upsurge economical in lenient power and community negotiation is essential to increase a nation's contour. He correspondingly highlights "the most operative announcement frequently happens not by unfriendly transmission but in uncompromising acquaintances." (Mcguigan; 1996. 54) It is precarious to be conscious of in what way lenient authority can be castoff by way of community negotiation. Additional, he (1996) focus on clever authority as the superior constancy of solid power and lenient power in external policy.

\subsection{Cultural Negotiation and its history}

Cultural negotiation has turned out to be essential of community negotiation by way of globalization in the common sense of bonding in financial and national life through the biosphere has been mounting for times. Through an increase of lenient influence, the word "Cultural Negotiation" has been confronted description misperception with comparable arguments such as global cultural discussion, cultural community associations, and national collaboration. By way of observing at standard trainings, cultural negotiation is mentioned to such as connotation from tangible application arrangement. Milton Cummings (2003), believes that cultural negotiation has been determined in place of "the discussion of thoughts, data, art, literature, music and additional facets of principles between countries and their populates with the purpose of nurture related considerations." (cumming; 2003, 34) This one describes cultural negotiation is in traditional happenings that a nation's impression of themself is finest characterized so as to carry on to stimulate publics the sphere done notwithstanding governmental dissimilarities and annoyed restrictions. Baudrillard expresses that cultural negotiation is to conversation thoughts, facts, arts, painting, literature, sculpture, music and dance and also culture to encourage reciprocated considerations between residents or dissimilar republics. (Baudrillard; 1988, 54) She emphasizes (1988) that cultural negotiation ought to be measured equally multifaceted viewpoints to escape one sided culture strategy for instance compulsion of employing philosophy and strategy to the realm as complete or public associations merely to stimulate its languages development. Brown (2006) likewise others delineate cultural negotiation such as self-absorption approaches of external procedure preferred by means of a country's cultural benefits. $\mathrm{He}$ accentuates it requirements to be measured from side to side stereoscope revelations for the reason that miscellaneous performers like administration figures, non-organizational establishments and characters are capable to comportment cultural negotiation. Cultural negotiation historically has concentrating on fortification and marketing of the particular general culture in the development of intercontinental altercation. "On the other hand lower than the specified pronunciation of globalization, the attention cannot be established exclusively on the concentration of states some extra". (Brown; 2006, 71) In opposition, universal traditional altercation cannot be disconnected from national benefits either one. Consequently, the inspiration of community, secluded and provincial performers in the understanding of actual cultural altercation sequencers is uncertainty increasing. Likewise the prerequisite for an improved appointment in persons-to-persons negotiation end to end with a cavernous appreciative of global cultural altercation has always been additional noteworthy. Brown pronounces (2006) the connection concerning culture and 
government has changed later 1940s. He also says that France, Britain and Germany engrossed on cultural growth through cultural relationships sequencer previously 1914s. Quickly extra nations monitored the tendency, Great Britain recognized the British Assembly for Relationships with additional nations in 1934 and the United States shaped the Agency on Assistance with the additional American Nations in 1938 and set of connections the Separation of Cultural Associations in the Department State satisfactory to encounter the necessity for general understanding. (Brown; 2006, 64) For the duration of the Cold War, the United States administration maintained altercation platforms for scholars and performers in the 1936 Agreement for the Advancement of American Cultural Associations, the perfect for the several altercation packages fundamental community negotiation. It supported the extent of American information, abilities, and thoughts in the combat of thoughts by Soviet Union. Particularly the Data and Instructive Altercation Act of 1948 was fruitful cultural negotiation strategy to encourage healthier appreciative of the United States. On the other hand, afterward of Cold War, cultural negotiation stopped to be a main concern up until 1960s. In 1975s, external program has altered significantly as viewpoint has been measured as well-organized implements of negotiation. Cummings (2003) portrays the traditional negotiation by telling it is fundamentally complicated consolidation a republic's cultural inspiration by backing artist's journey or by encouraging the learning of the nation's language and art, music, and literature in universities in a foreign country. (Cummings; 2003, 22) At what time the Age of Information has attained researchers lay emphasis on the prominence of the intercontinental cultural agenda for the reason that cultural harvests are progressively removed into the trans-national announcement and financial currents instigated by globalization. Finn also (2003) stressed that "to be traditionally authoritative or even culturally noteworthy in today's world, a nation need to work out to regulator in excess of these currents" (Finn; 2003, 19) which specifies cultural negotiation can be demarcated as the consciousness rising of culture by external strategy.

\section{Discussion}

\subsection{Constructions of Cultural Negotiation}

Cultural strategy architects must consider procedure bases cross management containing cultural conventions such as broadcasting procedure, training, official document and suppression regulation, overtax. Correspondingly they had better expedite Investigation and Expansion Centers to explore and shape up natural and original information and to successfully conjoin with native folks. Cultural procedure creators also must intemperance prejudiced feelings when distributing extraordinary art and general art. Art, literature, painting, dancing and culture of all diverse categories and forms can be prevalent or detested. Cultural strategy should not be constructed on prejudices around which art formulas are well intentioned of public maintenance, but on cultural standards that can noticeable themselves in numerous conducts, through several methods and categories. The cultural replacement projects must not be exaggerating to precise districts and nations, and it would promote national transaction sequencers with national atmospheres of each district and republic. Gienow and Dofried (2010) believe that cultural procedure creators must moderate needless administrative methods that disturb culture, art, music, and literature. (Gienow, Donfried; 2010, 65) Numerous performers and cultural administrations are reserved by contact to suitable organization, like settings and functioning planetary, in addition to absence of principal. The aptitude to fix in place strategy surroundings that permit them to accomplish, contemporary and create with boundless principal is further significant and operative in guaranteeing their accomplishment than straight subventions. In conclusion, national strategy manufacturers should contemplate inaugurating corporation with backing linkages that have chief purposes of emerging national negotiation and consolidation intercontinental stalemates. Cultural strategy requests to progress the manufactured organization method for mollification of the whole thing global cultural substitution, increase commercial sustenance, spread countless cultural subjects and impetus forward with miscellaneous packages for mutual cultural substitution out of one-sided cultural transaction.

\subsection{Cultural Individuality \& Globalization}

Cultural strategy creators can make an essential reclassification of the cultural uniqueness, not to national authority but the individuality of cultures to manage with massive influences on culture instigated by globalization. Globalization could distinguish paraphernalia on rudimentary standards and principles. (Plavsak; 2002, 31) Such as an outcome of the financial and cultural sound effects of globalization, composed with the impression of mass media such as cable TV, the Internet and portable phones, contemporary culture is confronted with amalgamation individualities. General public mature an intelligence of be appropriateness to a international art, music, and literature, by accepting observes, panaches, and data that are fragment of the international culture, which then generates a worldwide individuality. On the other hand, societies carry on to grasp their native individuality additionally, constructed on their societal to their indigenous beliefs. Therefore, distinct individuality is predisposed by equally a native and worldwide individuality. As a result, for national strategy it is vital that creators preserve a national individuality by possession national standards, social crowd, and general individuality persistent. Cultural individuality can be measured a lenient and smart power benefit for the reason that it developments its standards, philosophy and standpoints into World Wide Web.

Developing technologies will create it calmer to mixture cultural accomplishments with old-fashioned political effort by increasing the prospects for associates among populate. Latour believes (2005) that consequently cultural strategy creators must contemplate social reserve and functioning measures to mature national individuality finished industrial enhancement and invention. (Latour; 2005, 23) The world remains opening to distinguish the prominence of national negotiation equally the resources of lenient influence, and it stands significant to contrivance and accomplish miscellaneous national interactions and unindustrialized operative announcement over and done with facts machineries meanwhile the Internet has been quickly developing and it currently touches our everyday exists in particular manner 
and communal broadcasting facilities and transporting countries and persons faster self-possessed. It is tough to separate national strategy after the accessible atmosphere; henceforward strategy creators essential to smear additional exertion in emerging operative approaches of endorsing national negotiation done evidence machineries laterally with calculated national strategy structures.

\subsection{Cultural Negotiation in World Wide Web}

Information technology (IT) is modifying negotiation in numerous of the equal methods that they are transmuting cultures. In harmony with the evolution, national strategy creators can afford innovative exercise and specialized expansion occasions for community relationships generals taking accountability for community negotiation and social international relations during their professions, by specific consideration to study, polling, and the practice of original mass media. Bound declares (2007) to have information technology group's confidential consulates to successfully answer and gain worldwide friendliness, administrative improvement and commercial occasions specified that ended a billion of the world's inhabitants have contact to the Internet. (Bound; 2007, 10) The ability of governments at maintenances can be associated in applied crowds through relations through the world and relate developing knowledge entirely. The practice of information technology is to assistance comportment intercontinental associations. To progress connection with markers or ground processes, it is compulsory to employment an extremely cultured, combined and devoted creation supported broadcastings organization. Furthermore, relations to additional administration subdivisions and to community systems are essential. Such as, together constituent part and consulate websites have been industrialized in an appropriate method. An extensive diversity of evidence would be accessible, such as lightweight advisories, existing investigation and high-profile subjects, in addition to contacts to the continuously increasing and previously powerful substructure of administration locations and community places.

\section{Conclusion}

Cultural negotiation suggests give-and-take cultural interactions concerning populates to encourage general beliefs and assistances. It's supposed that national negotiation would encourage individuals done the world notwithstanding governmental dissimilarities and national limitations by means of lenient and smart authority would be improved over and done with cultural negotiation. Additional, it is predictable to improve appointment in societies to societies negotiation established on mutual considerations of national welfares. Through the appearance of the information period, information technology is having an extensive impression on in what way national strategy creators would interrelate through the community. Likewise it affects general individuality for the reason that a fresh beliefs has been shaped in World Wide Web and together the native and singular individualities are pretentious. Consequently, national individuality of a country has been mixed in line for swift connecting information technology. Today's information technology alongside with social strategy creators must have tactical structures for beliefs conversations; mature an essential national individuality in harmony through globalization and determination national negotiation into World Wide Web by means of having extremely refined information technology crews. Definitely, national negotiation in the globalization period would be stimulated to efficiently get used to innovative machineries. Eventually, the aim of cultural negotiation is to inspiration an external addressees and customs that inspiration, which is constructed up in excess of the extended period, as a category of respectable will replacement to success provision for strategies. It pursues to connect the rudiments of nation to persuade outsiders to:

- Consents the administration to generate a grounds of trust and a mutual appreciative that is unbiased and constructed on people-to-people interaction.

- Preclude, accomplish and alleviate skirmish through the marked population.

- Have an optimistic interpretation of the nation's persons, beliefs and programs.

- Assistance in fluctuating the strategies or party-political surroundings of the marked population.

- Persuade superior collaboration amid the populations from two countries.

- Allegations going from general sanctuary to accumulative tourism and profitable openings.

- Facility to stretch minority, youth and other addressees freestanding of the customary delegation course.

Cultural negotiation correspondingly cans assistance a population superior comprehend the external country it is promised with and substitute shared considerate and this traditional negotiation could be a technique of shepherding global relationships deprived of supposing no matter which in reappearance in the approach that customary negotiation characteristically anticipates. Traditional discussion databases drudgery by way of an average to communicate an auspicious impress of the extraneous nation with the intention of achievement foreigners' sympathetic and endorsement in their national observes and accept their communal customs between further nations. Usually, national negotiation is additional absorbed on the extended period and fewer on precise strategy materials. The determined is to shape up inspiration done the stretched period for at what time it is desirable by fetching individuals in a straight line. In summary, cultural negotiation plants the foundations of standards, thoughts, administrative influences, mystical awareness and an overall interpretation opinion of the realm that might or possibly will not embellishment in an external population. Cultural negotiation, correspondingly recognized as communal negotiation consequently that includes the comprehensive environment of old-fashioned community or national negotiation and mentions to the cultural applies over and done with arithmetical and networked tools, Internet, portable procedures, and social broadcasting stations. The present scuffle in contradiction of multinational extremism is a tussle to gain emotions and 
attentions, and the existing overreliance on firm authority on your own is not the pathway to accomplishment. Community negotiation is a significant implement in the resource of smart power, but profound community negotiation necessitates a considerate of the characters of reliability, self-deprecation, and domestic civilization in creating soft and smart power.

\section{References}

Baudrillard, J. (1988) The Ecstasy of Communication; Brooklyn, N.Y. Autonomedia.

Baudrillard, J. (1994) Simulacra and simulation; Ann Arbor: University of Michigan Press.

Beardsworth, R. (2010) Towards a Critical Culture of the Image; In J. Derrida and B. Stiegler.. Entretiens Filmes, Galile-INA, Paris: Tekhnema.

Bound, K. (2007) Cultural Negotiation; Oxford: University Press.

Brown, John. (2006) Arts diplomacy: The neglected aspect of cultural diplomacy. In America's Dialogue with the World, Washington, DC: George Washington University.

Belanger, Louis. (1999) Redefining Cultural Negotiation: Cultural Security and Foreign Policy in Canada; Political Psychology.

Cummings, M. (2003) Cultural Negotiation and the United States Administration: A Review. Center for Arts and Culture, vol. 1.

Cummings, Milton (2003) Cultural Diplomacy and the United States Government; Washington, D.C: Center for Arts and Culture.

Finn, K. (2003) The Instance for Cultural Diplomacy; Interesting Foreign Observers, External Affairs, Vol. 82.

Fotopoulos, T. (2001) Globalization, the Reformist Left and the Anti-Globalization Movement, Democracy \& Nature; the International Journal of Inclusive Democracy, Vol.7, No.2.

Joseph S. Nye, (2004) Soft Power: The Means to Success in World Politics; Cambridge: Perseus Books.

Hwajung, K. (2011) Cultural Diplomacy as the Means of Soft Power in an Information Age; Vintage Books.

Gienow J. \& Donfried, M. (2010) Searching for a Cultural Negotiation; Berlin: Berghahn Books.

Latour, B. (2005) Reassembling the Social: An Overview to Actor-network-theory. Oxford: Oxford University Press.

Mcguigan, J. (1996). Culture and the Public Sphere; London: Rutledge, University Chicago Press.

Plavsak, Kristina. (2002) Communicative Diplomacy; Journal of Political Marketing. 12 (3).

Richard T. (2005) The First Resort of Kings: American Cultural Diplomacy in the Twenties Century. Washington D.C., Potomac Books. 